\title{
Post-angiography headaches
}

\author{
Raquel Santos Gil-Gouveia - Rita Fernandes Sousa • \\ Leonor Lopes · Jorge Campos · Isabel Pavão Martins
}

Received: 21 May 2008/Accepted: 11 July 2008/Published online: 31 July 2008

(C) Springer-Verlag 2008

\begin{abstract}
Headache is a common symptom after cerebral angiography, although it has seldom been studied. We aimed to evaluate the frequency of headache at $24 \mathrm{~h}$ and 6 months after angiography and to describe its characteristics. We used a cross-sectional survey of consecutive patients submitted to angiography and determined headache presence and its characterization. Headache occurrence was analyzed against headache history, clinical data, technical and demographical variables. Of 107 procedures studied, $51.3 \%$ patients experienced headaches within $24 \mathrm{~h}$. Patients more likely to experience headaches were females or had subarachnoid hemorrhage. Six months post-procedure $48.8 \%$ of patients had frequent headaches. These patients had a positive headache history before the procedure, migraine in particular. Half of patients undergoing routine angiography experience benign post-procedure headaches within $24 \mathrm{~h}$ (especially women), yet it does not seem to predispose to chronic long-term headaches.
\end{abstract}

Keywords Angiography - Therapeutic embolisation · Headache $\cdot$ Migraine $\cdot$ Endovascular procedures

\footnotetext{
R. S. Gil-Gouveia · I. P. Martins Institute of Molecular Medicine, Lisbon's Faculty of Medicine, Hospital Santa Maria, Lisbon, Portugal

R. F. Sousa · L. Lopes · J. Campos

Neurorradiology Unit, Radiology Department,

Hospital Santa Maria, Lisbon, Portugal

R. S. Gil-Gouveia ( $\square)$

Laboratório Estudos de Linguagem,

Hospital de Santa Maria,

piso 8, Av. Prof. Egas Moniz, 1600 Lisbon, Portugal

e-mail: rgilgouveia@gmail.com
}

\section{Introduction}

The safety of cerebral angiography has greatly evolved since its development by Moniz [1], yet the prevalence of neurological complications is still 2.3\% [2]. Estimated headache incidence after cerebral angiography is $0.3 \%$ [3] although a $43 \%$ prevalence of migraine headache after angiography was described in migraine patients [4].

One study [5] designed to identify post-angiography headache used a small sample of cerebrovascular patients and reported $33 \%$ incidence of post-angiography headache. The International Classification of Headache Disorders [6] does not recognize post-angiography headache, only headaches starting during angiography or within $24 \mathrm{~h}$ of embolization.

We aimed to study post-procedure headaches, in order to (1) establish its frequency, (2) identify predisposing factors to its occurrence and to (3) determine its relation to previous headaches.

\section{Methods}

A prospective cross-sectional observational study was conducted on consecutive adult patients undergoing digital subtraction angiography (DSA) in a University Hospital; the study protocol was approved by the Hospital's Ethical Committee. Comatose, confused and non-consenting patients were excluded. Recruitment terminated with the inclusion of the 100th diagnostic DSA.

A semi-standardized interview was applied before the procedure, with demographic, clinical and technical data, screening, characterization and classification [6] of previous headaches, angiographic findings and/or therapeutic results. One to 5 days after the procedure, an author 
blinded to previous history applied an identical interview to each patient and registered current clinical status; the same evaluation was made 3-8 months later, by telephone.

SPSS v11.5 was used; frequency analysis performed with non-parametric tests, hypothesis on differences in means between groups tested by independent samples $t$ test. $\mathrm{P}<0.05$ was considered significant. The relation between post-procedure headaches and the risk factors found significant in bivariate analysis was studied with binary logistic regression; the best fit chosen based on likehood ratio.

\section{Results}

A total of 107 patients (67 females, age $52 \pm 16.3$ ) and 122 procedures were included; only the first procedure of each patient was analyzed, summing 86 diagnostic DSAs, 19 embolizations and two angioplasties studied. Indications for DSA were subarachnoid hemorrhages (32 patients), stroke (20) and others (unruptured aneurisms, post-therapeutic controls, AVMs, arteriovenous fistulae, tumor). Therapeutic procedures were embolizations of aneurysms (ten), AVMs (three), arteriovenous fistulas (four), tumor rammi (three) and carotid stenosis stenting (one).

Previous history of headache was reported by $47(43.9 \%)$ patients; 23 with secondary headaches [6] and 12 migraine. Female gender was related to the presence of previous headaches $(P=0.005)$.

Seventy-eight $(72.9 \%)$ patients were available for revaluation occurring on an average $28 \pm 15 \mathrm{~h} 54$ min after the procedure (mode $24 \mathrm{~h}$ ); lost patients were early discharged (12) or had impaired communication (ETE, aphasia, coma, confusion). Forty (51.3\%) patients reported headaches since the procedure-17 continuous pain, 12 a single headache episode and 11 several episodes (average $4.4 \pm 5.5)$. A headache-free interval between the procedure and pain onset occurred in 31 patients, lasting $10.4 \pm 7.6$ h. Headache was a mild (59\%) stabbing (45\%) bilateral $(55 \%)$ pain referred to the trigeminal territory $(66.7 \%)$. Most cases were without photophobia $(61.5 \%)$, phonophobia $(56.4 \%)$, nausea or vomiting (84.6\%). Headache was classified as migraine in three patients (one with previous migraine), tension-type headache (nine) and secondary in 28 patients.

Female gender $(P=0.013$, RR $2.50,95 \%$ CI $1.34-4.68)$ and diagnosis of aneurysm or SAH $(P=0.022, \mathrm{RR} 2.16$, 95\% CI 1.41-3.33) were risk factors for post-procedure headaches. Separate group analysis of $\mathrm{SAH}$ patients $(N=30)$ identified younger age $(55.3$ vs. $68.9, P=0.034)$ and lower average contrast dye iodine concentration (327.6 vs. $357.1, P=0.033)$ to relate to headache occurrence in these patients. In patients without $\mathrm{SAH}(N=48)$ only female gender $(P=0.005)$ presented as a risk factor, yet sample was too small to calculate relative risk.

A telephonic evaluation performed $164 \pm 61.6$ days post-procedure included 82 patients $(63.4 \%$ females, age $51.3 \pm 16.8$ ); patients lost to follow-up were due to impossibility of telephonic contact and death (one). Forty patients $(48.8 \%)$ described recurrent headaches since the procedure, 12 of which related its onset to the procedure. Seven patients had less than a total of four attacks; the remaining had $20.7 \pm 33.6$ episodes monthly, ranging from one every 2 months to five daily attacks. The episodes lasted less than $12 \mathrm{~h}$ in $75 \%$ patients, average duration $2.7 \pm 5.2 \mathrm{~h}$. Six patients had daily persistent headaches.

Headaches were mild $(62.5 \%)$ unilateral $(60 \%)$ nonthrobbing $(76.9 \%)$ pain in the trigeminal territory without associated nausea/vomiting (72.5\%); 50\% had photophobia and effort intolerance, $60 \%$ phonophobia. Headache was classified as migraine (12), tension-type headache (20) and secondary $(8)$ with positive correlation $(P=0.008)$ to the same previous headache diagnosis. Headache at 6 months was more likely in patients with previous headaches and migraine. Patients, grouped by initial headache diagnosis and presence or absence of headache at reevaluations, are depicted in Figs. 1 and 2.
Fig. 1 Previous headache diagnosis and headaches at each revaluation $(24 \mathrm{~h}$ and 6 months); 1st Ev (24 h): evaluation $24 \mathrm{~h}$ after the procedure; 2nd Ev (6 m): evaluation 6 months after the procedure; $X$ axis represents previous headache history; Numbers illustrated are patients counts within each group

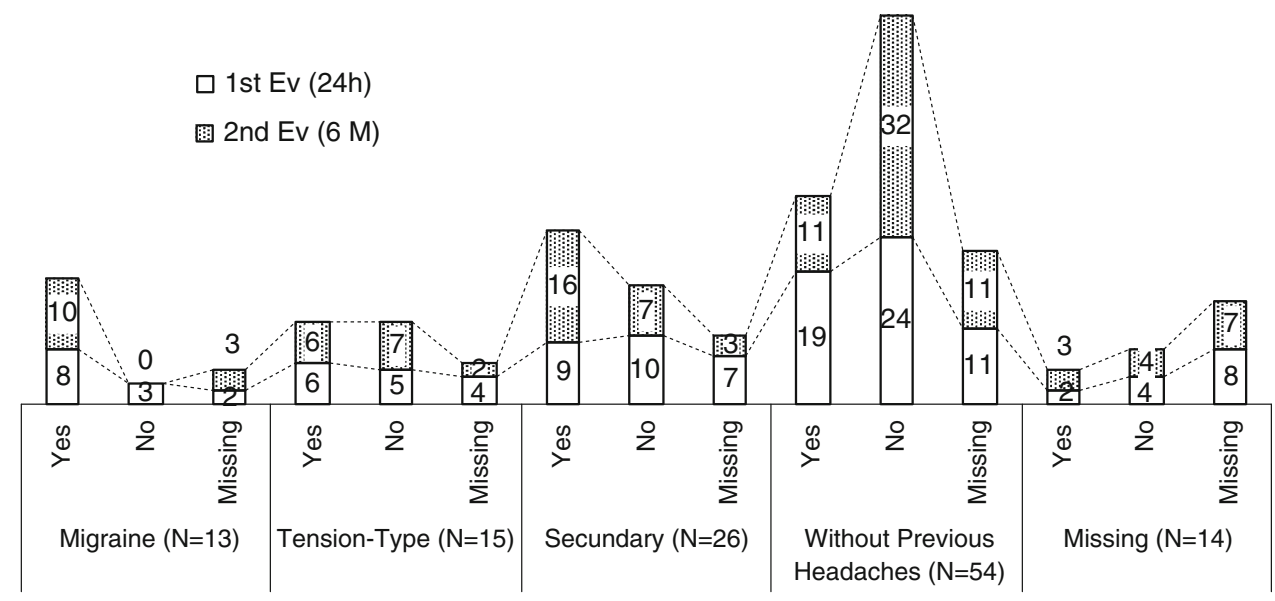




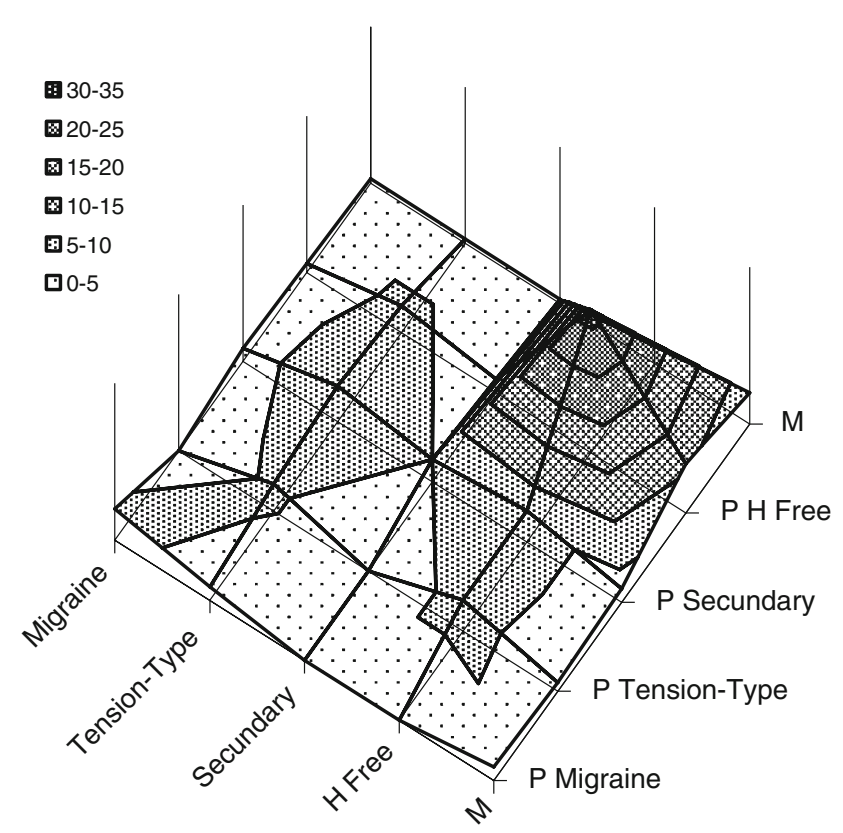

Fig. 2 Relation of headache diagnosis 6 months after the procedure to previous headache history; $X$ axis: headaches the 6 months revaluation; $H$ free: headache-free without headaches; $M$ : missing data; $Z$ axis: recurrent headaches before the procedure; $\mathrm{P} H$ free: previously headache free; $\mathrm{P}$ secondary: previous secondary headache; $\mathrm{P}$ tension-type: previous tension-type headache; $\mathrm{P}$ migraine: previous migraine, M: missing; $Y$ axis: number of patients in groups, as depicted in the gray-shaded legend

\section{Discussion}

Headaches after angiography are common, yet information about them is insufficient-its "benign" character is probably the reason why prospective series evaluating DSA complications fail to screen for headache [2].

We report $35.4 \%$ incidence of headaches $24 \mathrm{~h}$ after angiography (excluding SAH patients) in agreement with published data [5]. We could not identify "typical" postprocedure headache characteristics, probably reflecting its multifactorial etiology. Female gender was the only risk factor for post-procedure headache occurrence-a higher prevalence of most headache types on females has been documented in epidemiological studies [7] probably due to hormonal or pain perception threshold issues [7-9]. In opposition previous data [5], we did not find a relation neither with previous headaches nor migraine. Postprocedure headache onset had a delay of hours after the procedure-a fact previously reported $[4,5,10]$ that has been attributed to a triggering effect of cerebral angiography in susceptible individuals [5]. In our series, postprocedure migraine was rare (three patients).

Case reports of post-angiography migraine [10-12] after DSA or embolizations for cerebrovascular disease [11], vascular malformations and cortical dysplasia [10, 12] were described. In four cases, intra-angiographic onset of vasospasm in the posterior brain regions occurred, then typical aura developed with subsequent headache [11]; one case had vasodilatation of the fronto-temporal meningeal vessels $24 \mathrm{~h}$ after the onset of a migraine-like headache without aura [12]. It is possible that direct or indirect arterial stimulation induces the cortical spreading depression phenomena and consequent migraine-like headache, sometimes preceded by focal neurological symptoms localizing blood flow changes [13]. As with our series, some of these patients did not have previous migraine.

To our knowledge, this is the first study on late recurrent post-procedure headaches. Data suggests a relation to previous headaches (migraine in particular) so probably it is just a reflection of its recurrent pattern. Patients often relate the onset/aggravation of complaints to procedures; in our series, $19.6 \%$ of patients without previous headaches described new-onset headaches since the procedure, representing $22.5 \%$ of patients with recurrent headaches 6 months post-procedure. The explanation maybe a higher valorization of headache complains after an invasive intervention, also conditioned from increased self awareness and learning that headache can be a warning sign of intracranial pathology.

In conclusion, early post-angiography headache is common and must be foreseen, especially in women; it tends to be a mild headache starting a few hours after the procedure; so, a simple analgesic scheme prescribed si opus sit can promote comfort. Migraine is rarely triggered by cerebral endovascular procedures. Angiography does not seem to influence the occurrence of chronic recurrent headaches; causality remains to be determined in the minority of patients whose chronic headaches develop after angiography.

Conflict of interest None.

\section{References}

1. Moniz E (1927) Encéphalographie artérielle: son importance dans le diagnostic des tumours cérébrales. Revue Neurologique 1:48-72

2. Willinsky RA, Taylor SM, terBrugge K, Farb RI, Tomlinson G, Montanera W (2003) Neurologic complications of cerebral angiography: prospective analysis of 2899 procedures and review of the literature. Radiology 227:522-528

3. Heiserman JE, Dean BL, Hodak JA, Flom RA, Bird CR, Drayer BP, Fram EK (1994) Neurologic complications of cerebral angiography. Am J Neuroradiol 15:1401-1407

4. Shuaib A, Hachinski VC (1988) Migraine and the risks from angiogaphy. Arch Neurol 45:911-912

5. Ramadan NM, Gilkey SJ, Mitchell M, Sawaya KL, Mitsias P (1995) Postangiography headache. Headache 35:21-24

6. Headache Classification Committee of the International Headache Society (2004) The International Classification of Headache Disorders (second edition). Cephalalgia 24(Suppl 1):1-160 
7. Rasmussen BK, Olesen J (1992) Symptomatic and nonsymptomatic headaches in a general population. Neurology 42:12251231

8. Silberstein SD (2000) Sex hormones and headache. Revue Neurologique (Paris) 156(Suppl 4):S30-S41

9. Edwards RR, Haythornaite JA, Sullivan MJ, Fillingim RB (2004) Catastrophizing as a mediator of sex differences in pain: differential effects for daily pain versus laboratory-induced pain. Pain 111(3):335-341

10. Beekman R, Nijssen PCG, van Rooij WJ, Wijnalda D (2001) Migraine with aura after intracranial endovascular procedures. Headache 41:410-413
11. Olesen TS, Johansen AM, Skriver E, Herning MG (1990) Migraine with aura (classical migraine) in patients examined for cerebrovascular disease. Ugeskr Laeger 152:1513-1515

12. Kremer S, Grand S, Dananchet Y, Minotti L, Besson G, Ameur A, Kahane P, Le Bas JF (2002) MRI during postangiography headache. Neurology 58(9):1425

13. Parsons AA (2004) Cortical spreading depression: its role in migraine pathogenesis and possible therapeutic intervention strategies. Curr Pain Headache Rep 8:410-416 